Case Reports in
Gastroenterology
Case Rep Gastroenterol 2020;14:320-328

DOI: $10.1159 / 000508743$

Published online: July 1, 2020
(C) 2020 The Author(s)

Published by S. Karger AG, Basel www.karger.com/crg

This article is licensed under the Creative Commons Attribution-NonCommercial 4.0 International License (CC BY-NC) (http://www.karger.com/Services/OpenAccessLicense). Usage and distribution for commercial purposes requires written permission.

\title{
Successful Thrombectomy via a Surgically Reopened Umbilical Vein for Extended Portal Vein Thrombosis Caused by Portal Vein Embolization prior to Extended Liver Resection
}

\author{
Wouter J.M. Derksen ${ }^{a}$ Iris E.M. de Jong ${ }^{b}$ Carlijn I. Buis $^{b}$ \\ Koen M.E.M. Reyntjens ${ }^{c} \quad$ G. Matthijs Kater ${ }^{d} \quad$ Tijmen Korteweg $^{d}$ \\ Aryan Mazurid $^{\text {Robert J. Porte }}{ }^{\text {b }}$ \\ ${ }^{a}$ Department of Surgery, St. Antonius Hospital Nieuwegein, Nieuwegein, The Netherlands; \\ ${ }^{b}$ Department of Surgery, Section HPB Surgery and Liver Transplantation, University of \\ Groningen, University Medical Center Groningen, Groningen, The Netherlands; \\ 'Department of Anesthesiology, University of Groningen, University Medical Center \\ Groningen, Groningen, The Netherlands; ${ }^{d}$ Department of Radiology, University of \\ Groningen, University Medical Center Groningen, Groningen, The Netherlands
}

\section{Keywords}

Portal vein embolization · Hepatectomy · Umbilical vein · Thrombosis · Thrombectomy

\begin{abstract}
Selective portal vein embolization (PVE) before extended liver surgery is an accepted method to stimulate growth of the future liver remnant. Portal vein thrombosis (PVT) of the main stem and the non-targeted branches to the future liver remnant is a rare but major complication of $P V E$, requiring immediate revascularization. Without revascularization, curative liver surgery is not possible, resulting in a potentially life-threatening situation. We here present a new surgical technique to revascularize the portal vein after PVT by combining a surgical thrombectomy with catheter-based thrombolysis via the surgically reopened umbilical vein. This technique was successfully applied in a patient who developed thrombosis of the portal vein main stem, as well as the left portal vein and its branches to the left lateral segments after selective right-
\end{abstract}




\section{Case Reports in Gastroenterology}

Case Rep Gastroenterol 2020;14:320-328

DOI: $10.1159 / 000508743$

c) 2020 The Author(s). Published by S. Karger AG, Basel www.karger.com/crg

Derksen et al.: Surgical Reopening of the Umbilical Vein to Treat Extended PVT after Embolization

sided PVE in preparation for an extended right hemihepatectomy. The advantage of this technique is the avoidance of an exploration of hepatoduodenal ligament and a venotomy of the portal vein. The minimal surgical trauma facilitates additional intravascular thrombolytic therapy as well as the future right extended hemihepatectomy. We recommend this technique in patients with extensive PVT in which percutaneous less invasive therapies have been proven unsuccessful.

(C) 2020 The Author(s)

Published by S. Karger AG, Basel

\section{Introduction}

Selective portal vein embolization (PVE) is an accepted method to stimulate growth of the future liver remnant when extended liver surgery is planned for primary or secondary liver malignancies. PVE is associated with a high technical success rate $(>99 \%)$ and a low clinical failure rate $(<4 \%)$ [1]. Major complications related to PVE are rare with a reported rate of $<1-$ $4 \%[1,2]$. Portal vein thrombosis (PVT) of the portal vein main stem and/or the non-targeted branches to the future liver remnant is the most feared complication following PVE as this would be devastating for the curative options of the patient. Accidental thrombosis of the portal vein main stem or its branches to the future liver remnant requires emergent attempts to revascularize the vessels in order to restore portal flow to the future liver remnant. We here describe a successfully applied new surgical technique for revascularization of the portal vein via a reopened umbilical vein after massive PVT of the future liver remnant, which developed after selective PVE in preparation of an extended right hemihepatectomy.

\section{Case Report}

A 71-year-old female was referred to our quaternary referral center with a hilar biliary stenosis suspicious for a hilar cholangiocarcinoma (Bismuth classification 3A). She suffered from progressive jaundice, itching, and weight loss $(6 \mathrm{~kg})$ for the last 4 weeks. Blood test revealed an elevated bilirubin of $256 \mu \mathrm{mol} / \mathrm{L}$. She had a history of clinically stable Crohn's disease treated with infliximab. In 2013, she underwent curative treatment for a pT1cG1No infiltrating ductal adenocarcinoma of the left breast. Computed tomography (CT) scan revealed a tumor mass with encasement of the right hepatic artery and right portal vein, which was considered surgically resectable by an extended right hemihepatectomy after internal biliary drainage of the future liver remnant. Due to an insufficient volume of the left lateral liver remnant ( $22 \%$ of the total liver volume), we performed a percutaneous ipsilateral embolization of the segmental right portal vein branches, using polyvinyl alcohol embolization particles (Contour ${ }^{\mathrm{TM}}$ PVA Embolization Particles 45-150 $\mu \mathrm{m}$, Boston Scientific) and interlock coils (Interlock-18 Fibered IDC occlusion system, Boston Scientific). A postprocedural control angiography showed coiled right portal veins with a patent common and left portal vein (Fig. 1). Two days after this uneventful procedure, she presented at the emergency room with fever $\left(39.5^{\circ} \mathrm{C}\right)$ combined with nausea and headache. A CT scan was performed and revealed a successful embolization of the right portal vein; however, also a detrimental total occlusion of the common and left portal vein due to a massive thrombosis (Fig. 2). She was admitted to the hospital and treated with antibiotics intravenously (Clindamycin $600 \mathrm{mg} 3$ times daily and ciprofloxacin $400 \mathrm{mg}$ twice daily). Immediate portal vein thrombolysis was attempted by continuous intra-arterial infusion of the thrombolytic agent urokinase into the selectively catheterized superior mesenteric artery. Unfortunately, after 3 days of intra-arterial infusion of 


\section{Case Reports in Gastroenterology}

Case Rep Gastroenterol 2020;14:320-328

DOI: $10.1159 / 000508743$

c) 2020 The Author(s). Published by S. Karger AG, Basel www.karger.com/crg

Derksen et al.: Surgical Reopening of the Umbilical Vein to Treat Extended PVT after Embolization

urokinase, no signs of improvement were seen on the control CT scan. A transhepatic or transjugular retrograde cannulation of the portal vein was considered to be a nonrealistic treatment option due to the extent of thrombosis. No other minimally invasive treatment options were left to solve this major complication. Therefore, we attempted revascularization of the future liver remnant portal vessels by combining a mechanical thrombectomy of the left and common portal vein together with intraluminal catheter-based thrombolysis via a surgically reopened umbilical vein.

After induction of general anesthesia, we performed a (limited) bilateral subcostal laparotomy. No intra-abdominal signs of metastatic disease were found. After ligation of the umbilical ligament, we re-opened the obliterated umbilical vein with surgical forceps in a retrograde fashion until some retrograde backflow from the left portal vein was obtained. Next, the reopened umbilical vein was used to introduce a Fogarty balloon catheter into the left portal vein, and a significant amount of thrombus was removed from the common and left portal vein. Finally, we introduced a central venous catheter (CVC) through the umbilical vein and positioned the tip of the CVC at the base of the portal vein. We fixated the CVC to the umbilical ligament, peritoneal side of the abdominal wall and skin. After the operation, thrombolysis was initiated via the CVC with strict observation of the hemodynamics, plasma fibrinogen concentration and daily angiography via the CVC. Pathologic report of the removed thrombus showed a fresh thrombus with no signs of malignancy (Fig. 3). Control angiography after 1 day of thrombolytic therapy revealed recanalization of the left portal vein and portal vein main stem, but also remnant mural clots (Fig. 4a). Intraportal thrombolytic therapy was continued for another 2 days, after which control angiography demonstrated complete resolution of the PVT and the branches of the left portal vein to segment 2 and 3 of the liver (Fig. 4b). Thrombolytic therapy was discontinued, and a therapeutic dose of low-molecular-weight heparin was started. The same day, the patient developed abdominal pain, and a CT scan revealed a subscapular hematoma at the right side of the liver as complication of the thrombolysis and full-dose heparin treatment (Fig. 4c, d). The therapeutic dose of low-molecular-weight heparin was discontinued, and fortunately repeated imaging showed no progression of the subcapsular hematoma. After 4 weeks, CT volumetric analysis revealed a future liver remnant volume of $31 \%$ of the total liver volume. Accordingly, the patient underwent an uncomplicated extended right hemihepatectomy, including resection of the caudate lobe and extrahepatic bile ducts, followed by a hepatico-jejunostomy reconstruction. Because of a small persistent partial common PVT, we resected $1 \mathrm{~cm}$ of portal vein and reconstructed the vein by an endto-end anastomosis between the portal vein main stem and the left portal vein. Pathology report stated a 4-cm hilar cholangio-adenocarcinoma with invasion of the gallbladder with free resection margins and metastases in 3 out of 10 resected hilar lymph nodes (Fig. 5). After 19 days of an uneventful postoperative stay, the patient left the hospital in a relatively good clinical condition. She remained well for 2 years after surgery without any signs of recurrent PVT. Unfortunately, a CT scan performed due to abdominal complaints 2 years after the surgery revealed local tumor recurrence for which palliative care was started.

\section{Discussion}

To our knowledge, this is the first report presenting a surgical technique for revascularization of the portal vein via a reopened umbilical vein after massive thrombosis of the portal vein main stem and its branches to the future liver remnant, which developed after selective 


\section{Case Reports in Gastroenterology}

Case Rep Gastroenterol 2020;14:320-328

DOI: 10.1159/000508743

(c) 2020 The Author(s). Published by S. Karger AG, Basel www.karger.com/crg

Derksen et al.: Surgical Reopening of the Umbilical Vein to Treat Extended PVT after Embolization

PVE in preparation of an extended liver resection. The entire procedure is summarized in Figure 6.

PVT of the future liver remnant is a rare but devastating major complication following selective PVE. It requires emergent revascularization of the portal vein main stem and its branches to the future liver remnant. Without treatment, the patient is precluded from further curative partial liver resection and persistent PVT could result in an acute life-threatening situation.

PVE can be performed using several techniques [3]. The transhepatic, contralateral approach (puncturing the left portal vein and embolization of the right portal vein) is reported as easier compared to the transhepatic, ipsilateral approach, although there is possibility of endothelial injury of the portal branches to the future liver remnant [3]. These techniques to obtain access to the portal vein during PVE could be a risk factor for the development of PVT. Overall technical success rate of PVE is more than 99\% [1]. Major complications related to PVE are rare. The most recent review article, published in 2012, reported major complications such as PVT of the future liver remnant, liver hematoma, abscess, or bile leakage in less than $1 \%$ of all patients [1]. In 2014, Shindoh et al. [2] reported a major complication rate of $3.9 \%$ with a PVT rate of $2.2 \%$ in 358 patients after selective PVE. Overall reported PVE related mortality rate is $0.1 \%$ [1]. Although complications seem to be rare, PVT of the main stem and nontargeted branches is devastating for the patient.

In the presented case, the cause of PVT remained unclear. The patient did not have a history of coagulation disorders or liver disease. Spill of embolization particles in the common and left portal veins seemed very unlikely as these vessels reopened fully with thrombectomy and thrombolytic therapy several days later. During the PVE, we used the ipsilateral approach which has a very low risk of epithelial damage of the portal vein main stem and branches to the future liver remnant. However, there is a theoretical possibility of iatrogenic endothelial injury induced by intraluminal catheters into the common portal vein needed for contrast imaging during PVE.

The most frequently used embolization materials for PVE are polyvinyl alcohol particles, gelatin sponge, fibrin glue, n-butyl cyanoacrylate with lipiodol, polidocanol-foam, or combinations of these materials with coils or Amplatzer vascular plugs [1]. We used the polyvinyl alcohol particles together with coils. There is no evidence that the risk of PVT is different for the various PVE agents. Only direct intraportal alcohol injection has been associated with significantly increased morbidity rate and the development of PVT [4].

Local thrombolysis with thrombolytic agents via the superior mesenteric artery has been described as a successful method to revascularize the portal vein in cases of acute PVT [5]. Probably due to the extent of the thrombosis, this treatment was not successful in our patient. Other treatment options for PVT that have been described are transjugular or transhepatic catheter-directed thrombolysis [5]. Published case reports about successful treatment of PVT after PVE were cases in which embolization of the non-targeted portal branches were recognized during the embolization procedure [6, 7]. In these cases, immediate removal of the obstructed particles in the non-targeted vessels or immediate initiation of intraluminal thrombolytic agent was possible. It is likely that an acute thrombosis which is recognized immediately during the PVE procedure is better treatable compared to an older thrombosis which develops gradually after the PVE procedure. In our patient, the initial post-PVE angiography showed a patent common and left portal vein. Two days later, we were confronted with an out-clinic patient that presented with an extensive thrombosis of the portal vein main stem as well as the left portal vein branches. The extensiveness of the thrombosis made it less suitable for minimally invasive catheter-based thrombolysis. Therefore, we performed a surgical 


\section{Case Reports in Gastroenterology}

\begin{tabular}{l|l}
\hline Case Rep Gastroenterol 2020;14:320-328 \\
\hline DOI: 10.1159/000508743 & $\begin{array}{l}\text { @ 2020 The Author(s). Published by S. Karger AG, Basel } \\
\text { www.karger.com/crg }\end{array}$ \\
\hline
\end{tabular}

Derksen et al.: Surgical Reopening of the Umbilical Vein to Treat Extended PVT after Embolization

reopening of the umbilical vein to enable a combined mechanical thrombectomy and intraluminal infusion of thrombolytic agent to revascularize the portal vein main stem and its branches to the future liver remnant. Access to the portal vein system via a surgically reopened umbilical vein has previously been described by Soyama et al. [8] who used this technique to remove tumor thrombus from the portal vein main stem and its branches to the future liver remnant in a patient with hepatocellular carcinoma who underwent an extended right hemihepatectomy. A major advantage of accessing the portal vein system via a reopened umbilical vein is the lack of trauma to the portal vein itself. There is no need to explore the hepatoduodenal ligament and a portal venotomy which could lead to a stricture after closure. In our patient, we were able to start intraportal thrombolytic therapy with urokinase infusion immediately after surgery via a small catheter that was introduced via the umbilical vein. The lack of a freshly closed venotomy of the portal vein allowed us the start thrombolytic therapy immediately after the surgery.

The described technique is a relatively simple surgical procedure and demonstrates the possibility of revascularizing the portal system via the surgically reopened umbilical vein. Theoretically, this technique could be performed in every patient with an acute PVT and by every qualified surgeon. We recommend this procedure in patients in which PVT following PVE is too extensive for percutaneous treatment options. By considering this revascularizing technique, these patients remain eligible for curative liver surgery.

\section{Acknowledgements}

The authors like to thank Dr. E. Duiker (Department of Pathology, University Medical Center Groningen, The Netherlands) for her contribution to the pathology figures.

\section{Statement of Ethics}

Our case report complies with the guidelines for human studies and has been conducted in accordance with the World Medical Association Declaration of Helsinki. Our subject has given her written informed consent to publish her case (including publication of images).

\section{Disclosure Statement}

The authors have no conflicts of interest to declare

\section{Funding Sources}

We did not receive funding.

\section{Author Contributions}

W.J.M. Derksen: drafting, analysis, design, interpretation of data, final approval. I.E.M. de Jong: analysis, interpretation of data, final approval. C.I. Buis: drafting, analysis, design, 


\section{Case Reports in Gastroenterology}

\begin{tabular}{l|l}
\hline Case Rep Gastroenterol 2020;14:320-328 \\
\hline DOI: 10.1159/000508743 & $\begin{array}{l}\text { @ 2020 The Author(s). Published by S. Karger AG, Basel } \\
\text { www.karger.com/crg }\end{array}$ \\
\hline
\end{tabular}

Derksen et al.: Surgical Reopening of the Umbilical Vein to Treat Extended PVT after Embolization

interpretation of data, final approval. K.M.E.M. Reyntjens: analysis, design, interpretation of data, final approval. G.M. Kater: analysis, design, interpretation of data, final approval. T. Korteweg: analysis, design, interpretation of data, final approval. A. Mazuri: analysis, design, interpretation of data, final approval. R.J. Porte: drafting, analysis, design, interpretation of data, final approval.

All authors have approved the final version of the manuscript.

\section{References}

1 van Lienden KP, van den Esschert JW, de Graaf W, Bipat S, Lameris JS, van Gulik TM, et al. Portal vein embolization before liver resection: a systematic review. Cardiovasc Intervent Radiol. 2013 Feb;36(1):2534.

2 Shindoh J, Tzeng CW, Aloia TA, Curley SA, Huang SY, Mahvash A, et al. Safety and efficacy of portal vein embolization before planned major or extended hepatectomy: an institutional experience of 358 patients. J Gastrointest Surg. 2014 Jan;18(1):45-51.

3 Loffroy R, Favelier S, Chevallier O, Estivalet L, Genson PY, Pottecher P, et al. Preoperative portal vein embolization in liver cancer: indications, techniques and outcomes. Quant Imaging Med Surg. 2015 Oct;5(5):730-9.

4 Shimamura T, Nakajima Y, Une Y, Namieno T, Ogasawara K, Yamashita K, et al. Efficacy and safety of preoperative percutaneous transhepatic portal embolization with absolute ethanol: a clinical study. Surgery. 1997 Feb;121(2):135-41.

5 Hidajat N, Stobbe H, Griesshaber V, Schroder RJ, Felix R. Portal vein thrombosis: etiology, diagnostic strategy, therapy and management. Vasa. 2005 May;34(2):81-92.

6 Dobrocky T, Kettenbach J, Lopez-Benitez R, Kara L. Disastrous Portal Vein Embolization Turned into a Successful Intervention. Cardiovasc Intervent Radiol. 2015 Oct;38(5):1365-8.

7 Shaw CM, Madoff DC. Acute Thrombosis of Left Portal Vein during Right Portal Vein Embolization Extended to Segment 4. Semin Intervent Radiol. 2011 Jun;28(2):156-61.

8 Soyama A, Eguchi S, Takatsuki M, Hidaka M, Muraoka I, Tomonaga T, et al. Tumor thrombectomy via a surgically reopened umbilical vein combined with right hemihepatectomy in a patient with hepatocellular carcinoma. Dig Surg. 2011;28(3):222-5.

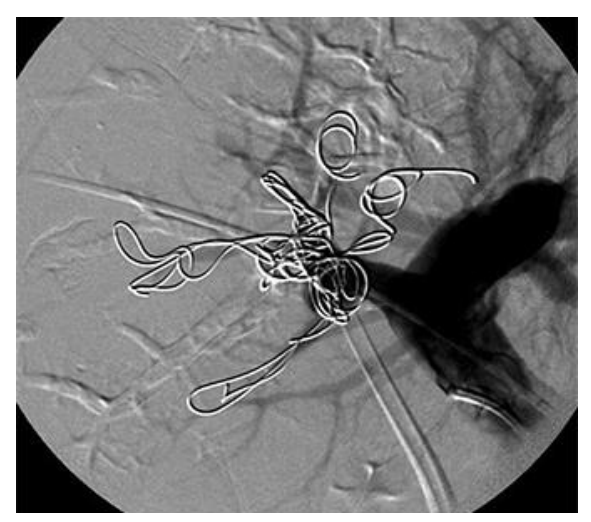

Fig. 1. Postprocedural angiography after selective embolization of the right portal vein with a patent common and left portal vein. 
Case Reports in Gastroenterology
Case Rep Gastroenterol 2020;14:320-328

DOI: $10.1159 / 000508743$

c) 2020 The Author(s). Published by S. Karger AG, Basel www.karger.com/crg

Derksen et al.: Surgical Reopening of the Umbilical Vein to Treat Extended PVT after Embolization
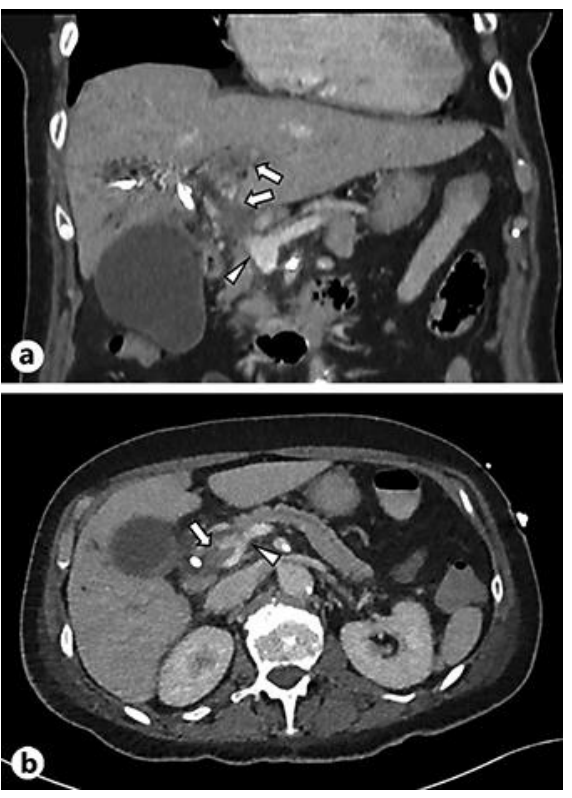

Fig. 2. CT scan revealed an extensive thrombosis of the portal vein main stem and its branches to the future liver remnant (segments 2 and 3). Thrombus is indicated by white arrows and the patent confluence of the superior mesenteric vein and splenic vein by arrowheads. a Coronal view. b Axial view.

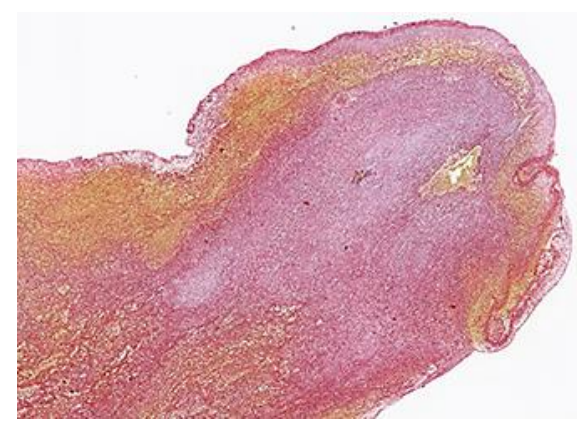

Fig. 3. A histological picture (Martius scarlet blue trichrome staining) of the fresh thrombus we removed from the portal vein. Fresh fibrin stains orange and mature fibrin red. Old fibrin stains blue, which was not present in the material. Images were acquired from digital slides with a $\times 0.5$ objective. 


\section{Case Reports in Gastroenterology}

www.karger.com/crg

Derksen et al.: Surgical Reopening of the Umbilical Vein to Treat Extended PVT after Embolization
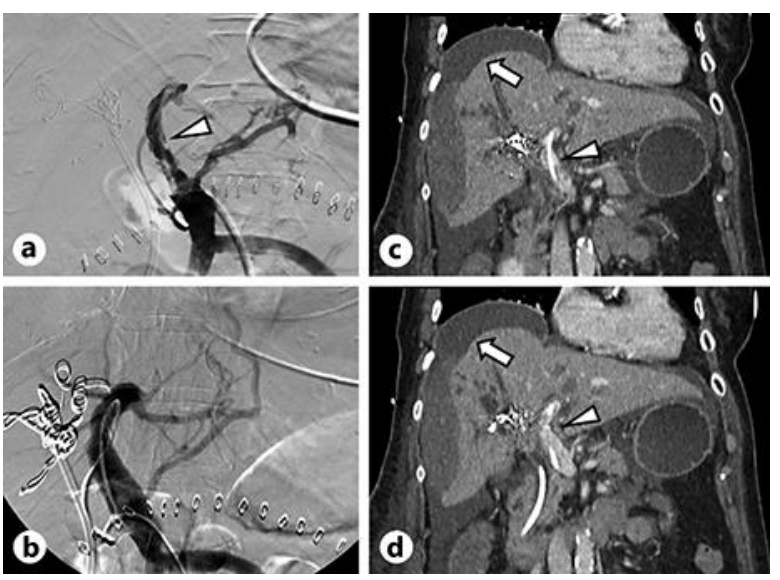

Fig. 4. Treatment of portal vein thrombosis. a Angiography 1 day after revascularization via the native umbilical vein showed restoration of blood flow in the portal vein main stem and the left portal branches with remnant mural clots (arrowhead). b Angiography after 3 days of intraportal thrombolytic therapy revealed complete lysis of the clot remnants and complete restoration of flow to the branches of the left portal vein. c, d CT scan after 3 days of intraportal thrombolytic therapy demonstrating a subcapsular hematoma of the right liver lobe (arrows) and a patent portal vein with the transumbilical vein catheter in situ (arrowheads).
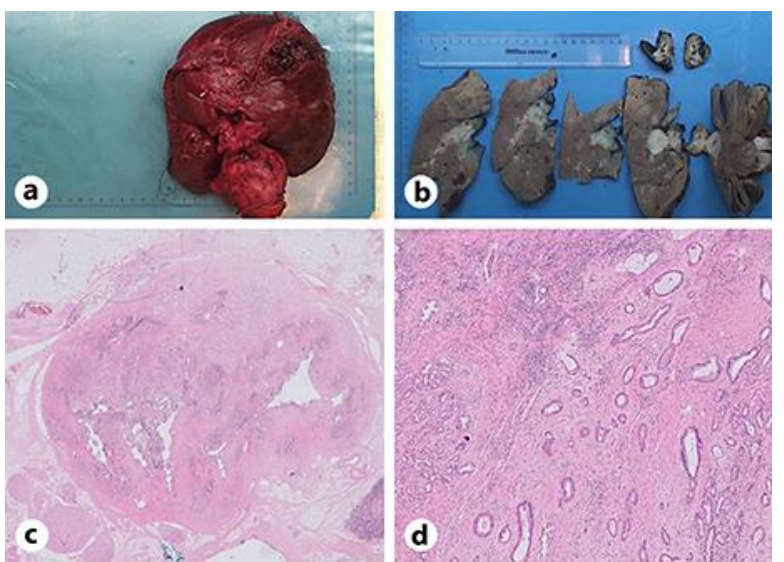

Fig. 5. Pathology and histology of the surgical resection specimen. a Macroscopic picture of the extended right hemihepatectomy specimen. $\mathbf{b}$ Laminated resection specimen with tumor invasion in the gall bladder wall (circular part of the tumor). c, $\mathbf{d}$ Detailed histological pictures (hematoxylin and eosin stains) with the tumor centrally situated (c) and surrounded by dysplastic epithelium (d). Images were acquired from digital slides with $\mathrm{a} \times 0.5(\mathrm{c})$ and $\mathrm{a} \times 5(\mathrm{~d})$ objective. 
Case Reports in Gastroenterology
Case Rep Gastroenterol 2020;14:320-328

DOI: 10.1159/000508743

(c) 2020 The Author(s). Published by S. Karger AG, Basel www.karger.com/crg

Derksen et al.: Surgical Reopening of the Umbilical Vein to Treat Extended PVT after Embolization
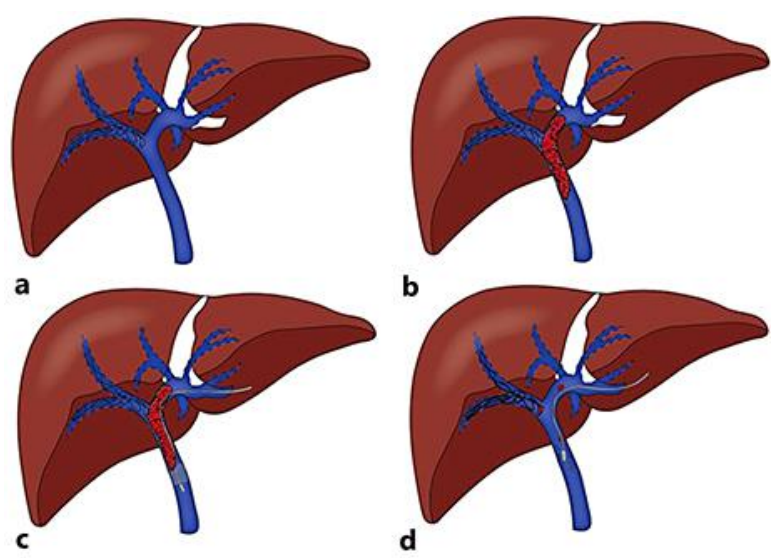

Fig. 6. Schematic illustrating the technique of surgical reopening of the obliterated umbilical vein to obtain access to the portal vein system with subsequent successful treatment of portal vein thrombosis. a Status after transhepatic elective embolization of the right portal vein. b Accidental thrombosis of the portal vein main stem and the left portal vein branches to the future liver remnant. c Thrombectomy via the surgically reopened umbilical vein giving access to the portal vein main stem via the left portal vein. $\mathbf{d}$ Additional thrombolysis via a catheter placed in the portal vein via the reopened umbilical vein. 